\title{
Discussion on Microteaching of English Major Students of Normal Schools
}

\author{
Yufeng $\mathrm{Xu}^{1, \text { a }}$, Yuanbin Zhou ${ }^{2, \mathrm{~b}}$ \\ ${ }^{1}$ Foreign Language School, Jiangxi Science \& Technology Normal University, Nanchang, China \\ 2 Jiangxi University of Science and Technology \\ a xuyuf8899@163.com; 'zhouyb8899@163.com
}

Keywords: microteaching; English major students of normal schools; problems

\begin{abstract}
How to improve the teaching ability of English majot students of normal schools and the skill training methods of classroom teaching is a subject with realistic significance. Microteaching provides a practical and scientific method for it and is the main way to improve the teaching skills of English major students of normal schools. The paper describes how to effectively carry out the microteaching in English major students of normal schools and the problems needing to pay attention to in microteaching.
\end{abstract}

\section{Introduction}

The teaching skill is the indispensable professional ability of English major students of normal students, and microteaching is the key link of cultivating and training the teaching skills of English major students of normal schools. However, many normal universities put a lot of effort to improve the students' English professional knowledge and ignore the teaching skills. Therefore, the microteaching of English major students of normal schools is a problem worthy of attention.

\section{How to effectively carry out the microteaching in English major students of normal schools}

Preparation stage. The preparation is very important and is directly related to the quality and effectiveness of microteaching. It includes the following steps. First of all, consolidate and review language teaching theory and practice knowledge. Before carrying out microteaching, English major students of normal schools should conscientiously summarize and consolidate the language teaching theory and practice knowledge learned from the curriculum of education (such as pedagogy, psychology, English teaching theory, teaching skill, teaching method dynamic, etc). In addition, learn some classroom teaching language systematically and how to organize the class successfully through observing the national or provincial English teaching videos. Secondly, determine and be familiar with specific implementation plan. Before two weeks of carrying out microteaching, the teachers responsible for the microteaching should do a good job in specific implementation programs. According to the English teaching textbooks and education practice of local schools, specify the specific teaching books and the teaching contents. Then do the group scheme and determine the classroom use time to make the appropriate arrangements. In addition, organize the expert of teaching method, especially the outstanding backbone teachers in middle schools to establish the evaluation standard of microteaching training. Write lesson plans carefully and carry out discussion before class. For the students of normal schools, they should make full use of the knowledge about teaching methods and prepare brief and detailed teaching plan on the basis of grasping the teaching contents. The brief teaching plan covers each part of the general teaching plan, including teaching background information, teaching content, teaching aim, teaching difficulty, teaching means, basic teaching steps, etc. Detailed teaching plan mainly focus on detailed teaching steps, including some classroom language, some answers students may ask, teaching theoretical basis of each step, etc. After finishing lesson plans, organize the micro group to discuss before class, so as to revise and perfect teaching plan timely. 
Class organization. In microteaching, class organization mainly includes teachers' manners, multi roles, rationality of teaching decision, etc. firstly, teachers' teaching manners and multi roles. Good teaching manner is the necessary professional quality of an excellent English teacher and an important factor to control the classroom order. Because the students of normal schools have never served as the role of teacher, it is difficult for them to establish good teaching manner. When developing the micro teaching, due to anxiety, some students may lack eye contact and enthusiasm, etc. In the process of classroom organization, teachers should strive to achieve the change of multi roles, such as facilitator, negotiator, participant, etc. secondly, the accuracy of teachers' classroom language and instruction. Classroom language and instruction is one of the most important elements in English teaching and throughout the whole process. Accurate and fluent language and instruction is not only beneficial to language input, but also contributes to the organization of classroom teaching. Generally speaking, the classroom language in English class should be accurate, easy to understand and close to the objective. The teaching instruction should also be simple and easy to understand. For the students of normal students, they cultivate the ability through observing English teaching video, making records and constantly summarizing on teachers' classroom teaching language and instruction. Thirdly, rationalization of classroom teaching decision making. Teaching decision-making, throughout the teaching, is an important part of classroom teaching. Due to lack of teaching experience, students of normal schools are difficult to predict and coordinate some problems in teaching, and even are helpless when dealing with emergencies, such as they can not adjust the lesson plan according to the actual reaction of students. To ensure the rationality of decision of classroom teaching, teachers need to know the teaching objects, be familiar with teaching content and objectives, and have certain teaching belief, knowledge and some practical understanding.

Evaluation and reflection after microteaching. Evaluation is an important and indispensable part of microteaching. Scientific and reasonable evaluation can make the students of normal school have more clear direction, understand their own advantages and problems in training, and experience the success and reflect the failure according to the evaluation standard, so as to continuously improve their behaviors. Firstly, the evaluation of instructors. After the microteaching, teachers should conduct on-site reviews on the classroom teaching design and classroom organization combining with the specific teaching content, English standard and relevant language teaching theory. Teachers' comment should focus on the basic language skills (including pronunciation, intonation, oral expression, etc), basic teaching skills (including classroom language, teaching attitude, chalk, multimedia courseware, etc), the rationality of teaching design, etc. in short, the aim of teachers' comment should mainly encourage them and do not hurt students' teaching enthusiasm. Secondly, peer evaluation. Peer evaluation refers to the evaluation of groupers. The groupers can copy microteaching video, and then take the individual or collective discussion to carry out objective and effective evaluation according to microteaching evaluation standards through observing the teaching video. They can also make use of blogs, forums, Tencent Chat groups and other modern network platform to enhance the efficiency of evaluation. Thirdly, self evaluation and reflection. Self evaluation and reflection is an important way to promote the professional development of teachers. After microteaching, the speakers should repeat viewing their teaching video and describe the result of evaluation simply. At the same time, the speakers should reflect on their teaching carefully, summarize the advantages and disadvantages. In addition, they can compare their own teaching video with others to carry out teaching reflection from different dimensions.

\section{Problem should be paid attention to in English microteaching}

Since the inception, microteaching is widely used and popular. The reasons are: first of all, its purpose is clear and teaching method is novel; second, the feedback is timely enough; third, it is easy to evaluate. However, it still has some problems in the concrete implementation process. The main problems are the following. 
The feeling of freshness decreases. Microteaching and video feedback let the students of normal schools feel very excited. However, after several trials, their enthusiasm and excitement may drop. The students of normal school often pay attention to the first lens, and then become accustomed to it. Answering the questions in English class, collecting and reviewing the feedback, and the interaction between teachers and students, gradually become the program and formulistic act and speaking themselves, which is difficult to achieve a high degree of unity.

Simulation course is different from the real classroom. In English microteaching simulation class, about 10 students forms a simulated class. But the real high school has 40 to 50, even 60 to 70 students, the training effect is obvious. In addition, the student, acting as the teacher and student themselves, has the preparation and the same level, so the link of answer and question can be cooperated successfully, which has huge difference with real teaching in middle schools. Therefore, even if students of normal school succeed in simulation class, they may still appear bewildered and upset the teaching plan to affect the teaching effect seriously when back in the real teaching scenes.

Some misunderstandings exist in teaching links. At present, some universities implement slowly due to lacking of understanding. However, English microteaching is an organic system, teachers, students, teaching materials, media and the environment need to maintain a high degree of consistency. But in the specific training, it is often restricted by many environment factors, such as students of normal school are excessive; teachers are not enough and other reasons, will directly cause teachers to cut teaching links. For example, some teachers emphasis on making teaching plan while not connecting with the fact of students; some problems is too single and not conducive to cultivating students' ability; some teachers focus on the interaction between teachers and students and hold that a bustling class is a successful English class. All these factors will make the micro teaching divorce from the reality and not conducive to the improvement of teachers and students.

The management of microteaching is not perfect enough. First of all, in many normal colleges and universities, microteaching has not been officially listed in the teaching plan, therefore, microteaching fail to arouse the attention of teachers and students. Students have no enough time to train teaching skills, so the microteaching only can be carried out after school. Secondly, to complete the microteaching task, the workload of guiding teachers is quite large and needs great amount of energy. If the school can not calculate the workload of teachers correctly, it can not effectively mobilize the enthusiasm of teachers and affect the effective development and promotion of microteaching seriously. In order to solve these two problems, the management department, especially the educational administration department, should pay more attention to microteaching, incorporate it into the routine teaching plan, identify the specific the class time, and arrange excellent guiding teaching to instruct the microteaching.

Microteaching evaluation lack systematic evaluation standard. The evaluation criteria influences the result of microteaching directly. Due to the lack of organization, guiding teachers use different evaluation criteria, causing the students of normal schools helpless and blind. When making the plan of microteaching, the schools should establish a set of scientific evaluation index system to let the microteaching carried out smoothly and effectively. Systematic microteaching evaluation standard is conducive to the development of students, which not only focus on the observation of explicit behavior, but also emphasis on the implicit expression. Generally speaking, evaluation standard are mainly the quantitative evaluation index system, including the finger standard grade and standard description.

\section{Conclusion}

In conclusion, the quality of students from normal schools, as an important reserve force of English teaching in basic education, is directly related with English curriculum reform process. How to improve the teaching ability of English students from normal schools and perfect the skill training methods is a subject with realistic significance. Microteaching training provides a practical and scientific method for it. Under the guidance of people-oriented educational philosophy and new 
course reform, the national normal colleges should joint together to let English microteaching get rid of predicament and develop successfully.

\section{References}

[1] Xiankai Meng. Basic tutorial[M]. Beijing: Beijing Normal University press, 1996.

[2] Wentao Pan, Xuanwen Huang. Discussion on some problems of microteaching[J]. Audio-visual education research, 2005,(8):53-54.

[3] Zhongji Huang. Effective ways of improving teaching skills in colleges[J]. Journal of Lanzhou Institute of Education, 2006,(03): 40-42.

[4] Jun Wu. Micro teaching and students' ability cultication[J]. Journal of Xichang Teacher College, 2004,(03).

[5] Deyun Song, Sen Li. Teachers' teaching decision-making: connotation, form and significance[J]. Curriculum. Teaching materials. Teaching methods, 2008,(12):21-26.

[6] Zhenhai Wang. Application of microteaching in teaching skill training[J]. Audio visual education research, 2000(3).

[7] Lihong Mao, Chunlan Kang. How to use microteaching to improve the teaching ability of normal school students[J]. Education Forum, 2004(9).

[8] Lieqin. The situation and strategies of microteaching in normal colleges[J]. Journal of Shangluo College, 2008(1). 